\title{
TEMPOS E REDES: A ARQUITETURA DE UMA SALA DE AULA EM EAD
}

\author{
Ormezinda Maria Ribeiro* \\ Carmem Jená Machado Caetano**
}

\begin{abstract}
RESUMO
Nos últimos anos, tem-se intensificado a implantação de cursos de graduação na modalidade a distância nas instituições públicas, permitindo que a investigação de elementos importantes em relação ao processo de ensino aprendizagem realizado em EAD também faça parte de discussões relevantes no âmbito acadêmico. O desafio é o de incorporar as tecnologias de informação e comunicação, as TIC, tendo em vista esses aspectos, sem incorrer no equívoco de aliar o recurso tecnológico à concepção empirista da educação. Em tempos de educação em rede, o tempo pedagógico assume a dimensão temporal dedicada à produção de experiências significativas que levem o estudante à autonomia no processo ensino aprendizagem. A inserção das TIC é, em geral, vista como simples instrumentalização, mas sendo novas tecnologias sua relevância toma outros sentidos, compondo as assim ditas habilidades do século XXI. Nosso aporte teórico encontra respaldos nos trabalhos desenvolvidos por Lévy (2009) e Pais (2004). Nosso objetivo é assumir a postura de pesquisadoras que acreditam que é preciso encarar o desafio que está mais do lado educacional do que tecnológico e repensar o papel que a pedagogia assume nos dias atuais, bem como trazer à tona reflexões de trabalhos desenvolvidos com resultados positivos.
\end{abstract}

Palavras-chave: Tecnologia. Educação. Tempo pedagógico.

\begin{abstract}
TIMES AND NETWORKS: THE ARCHITECTURE OF AN E-LEARNING CLASSROOM

In recent years, the implantation of undergraduate courses by public institutions in the modality of distance learning has increased, allowing the investigation of important elements related to the process of teaching-learning done through e-learning $(\mathrm{EaD}$ in Portuguese) also be part of relevant discussions in the academic community. The challenge is to incorporate information and communication technologies (TIC), taking into account these aspects, without incurring the error of connecting the technological resource to the empirical conception of education. In an era of
\end{abstract}

\footnotetext{
* Doutora em Linguística e Língua Portuguesa pela Universidade Estadual Paulista Júlio de Mesquita Filho (Unesp- Araraquara). Professora adjunta na Universidade de Brasília (UnB). Endereço Institucional: Departamento de Linguística, Português e Línguas Clássicas - LIP- ICC SUL - Campus Universitário Darcy Ribeiro, Brasília-DF. CEP: 70910-900. aya.ribeiro@yahoo.com.br

** Doutora em Linguística e Língua Portuguesa pela Universidade de Brasília (UnB). Professora adjunta na Universidade de Brasília (UnB). Endereço Institucional: Departamento de Linguística, Português e Línguas Clássicas - LIP- ICC SUL - Campus Universitário Darcy Ribeiro, Brasília-DF. CEP: 70910-900. carmemjena@gmail.com
} 
networking education, the pedagogical time has a temporal dimension dedicated to the production of significant experiences that provide the student with autonomy in the teaching-learning process. TIC is generally seen as an instrument, but, being new technology, its relevance has other meanings, composing the so-called twenty-first century skills. Theoretical contributions here include works by Lévy (2009) and by Pais (2004). Our aim is, as researchers who believe that it is necessary to face the challenge that is more on the educational side than on the technological side, to rethink the role that pedagogy plays nowadays, as well as to reflect on developed works that had positive results.

Keywords: Technology. Education. Pedagogical time.

\section{Palavras iniciais}

$\mathrm{Na}$ última década, a Internet agregou uma perspectiva hipermidiática à nossa rede de inter-relações, mudando, inclusive, nossa visão de tempo e espaço. Mais recentemente, as ferramentas da web 2.0 (blogs, wikis, postcasts etc.) vêm ampliando as possibilidades para interações síncronas e assíncronas entre os alunos de diferentes partes do mundo que têm interesse em aprender juntos, colaborando para a coconstrução do conhecimento.

Além disso, as tecnologias fundamentadas no conhecimento em ação do professor, representadas pelas suas decisões de como ensinar conteúdos específicos, num certo tempo, com a finalidade de alcançar metas preestabelecidas, num determinado contexto sociocultural, formam soluções criativas para o processo de ensino aprendizagem.

Tradicionalmente, a aprendizagem de informações e conceitos era tarefa exclusiva da escola. Os conhecimentos teóricos eram apresentados gradativamente aos alunos após o ingresso nas instituições de ensino básico e logo depois, médio e superior. Eles eram finitos e determinados. Ao final de um determinado número de créditos em disciplinas no ensino superior, a pessoa podia considerar-se formada, ou seja, já possuía conhecimentos e informações suficientes para iniciar-se em alguma profissão.

O espaço e tempo de ensinar eram determinados. "Ir à faculdade" representava um movimento, um deslocamento até à instituição designada para a tarefa de ensinar e aprender. $\mathrm{O}$ "tempo da faculdade", também determinado, era considerado como o tempo diário que, tradicionalmente, o homem dedicava à sua aprendizagem sistematizada. Cor- respondia, também, à época, na sua história de vida, que o homem dedicava à formação profissional. No entanto, as velozes transformações tecnológicas da atualidade impõem novos ritmos e dimensões à tarefa de ensinar e aprender. É preciso que se esteja em permanente estado de aprendizagem e de adaptação ao novo. Não existe mais a possibilidade de se considerar a pessoa totalmente formada, independentemente do grau de escolarização alcançado. Além disso, múltiplas são as agências que apresentam informações e conhecimentos a que se pode ter acesso, sem a obrigatoriedade de deslocamentos físicos até às instituições tradicionais de ensino para aprender. Universidades virtuais oferecem vários tipos de ensinamentos on-line, além das inúmeras possibilidades de se estar informado, a partir das interações com todos os tipos de tecnologias mediáticas.

Em verdade "na atualidade, o que se desloca é a informação", diz Virilio (1993). E esses novos conhecimentos deslocam-se em dois sentidos: o primeiro, o da espacialidade física, em tempo real, sendo possível de serem acessados através das tecnologias mediáticas de última geração. $\mathrm{O}$ segundo, pela sua alteração constante, transformações permanentes, sua temporalidade intensiva e fugaz. Velocidade. Este é o termo síntese do status espaço-temporal do conhecimento na atualidade. Velocidade para aprender e velocidade para esquecer. Velocidade para acessar as informações, interagir com elas e superá-las com outras inovações. Se essa explosão de informação, de um lado, presta-se a criar meios cada vez mais eficientes para o armazenamento e a circulação instantânea de informações, de outro, desenvolve softwares e programas de busca e de filtro que nos ajudam a 
administrar um espaço que já beira o infinito, são as novas tecnologias, o redimensionamento do espaço e do tempo e os seus impactos no trabalho docente que vale a pena ser pensado. É claro que o fato de o homem viver entre diversos tipos de temporalidades será levado em conta. Na realidade, há uma percepção geral e intuitiva de que os múltiplos sentidos de tempo se entrecruzam na vida cotidiana.

Como nos lembra Kenski (1997), a percepção mecânica e objetiva, definida pelos relógios e calendários, orienta as nossas atividades rotineiras. Estabelece ritmos e nos auxilia operacionalmente a definir prazos e compromissos. Em um sentido consensual geral, o tempo determinado espacialmente pelos cronômetros, pela periodicidade dos meses e das estações do ano, ou pela delimitação de períodos ou eras, é uma imensa abstração. $\mathrm{O}$ homem ocidental subordina-se pragmaticamente às suas determinações - horas, minutos, segundos, meses, anos... - e orienta as ações de acordo com a sua imagem de "continuidade" e progressão.

A relatividade do tempo estudada pela Física aparentemente não interfere no sentido que o homem compreende o tempo na vida cotidiana. Nesta, o tempo do trabalho ou o tempo industrial é praticamente o denominador comum através do qual a grande maioria da população urbana atual se orienta e obedece. Essa temporalidade industrial, típica da sociedade capitalista, é vivida em todos os momentos, no trabalho ou fora dele.

Ainda de acordo com Kenski (1997), em nossas relações cotidianas não podemos deixar de sentir que as tecnologias - velhas, como a escrita, ou novas, como as agendas eletrônicas - transformam o modo como nós dispomos, compreendemos e representamos o tempo e o espaço à nossa volta. Sem nos darmos conta, o mundo tecnológico invade a nossa vida e nos ajuda a viver com as necessidades e exigências da atualidade. Secretárias, agendas, correios, listas, bancos e tantos outros serviços eletrônicos redimensionam as nossas disponibilidades temporais e os nossos deslocamentos espaciais. O tempo, o espaço, a memória, a história, a noção de progresso, a realidade, a virtualidade e a ficção são algumas das muitas categorias que são reconsideradas em novas concepções a partir dos impactos que, na atualidade, as tecnologias eletrônicas têm em nossas vidas.
A aceleração das transmissões faz desaparecer a separação entre o próximo e o distante. O tempo eletrônico ignora o tempo real. "O tempo veloz é um tempo ultracurto, contraído, em contraposição ao tempo extensivo, das longas durações", diz Moraes (1997, p. 28). As linhas divisórias entre o aqui e o além dependem do tráfego eletrônico e do horário das programações midiáticas. O tempo fica sem referencias, "sem raízes", como nos diz o autor.

Velocidade tecnológica estabelece uma nova relação entre o tempo e o espaço. O espaço como territorialidade, se altera. Assim como na tela da televisão, novos espaços invadem a sala de estar, e a tecnologia das redes midiáticas acelera a visita a novos espaços. Atualmente, a aceleração tecnológica, que se materializa na vida social, faz com que nosso tempo interno, imaginário, sofra pressões da vida urbana, e o externo tenha maior influência sobre o interno. A regulação do tempo exacerba-se.

A complexidade da temática faz-nos buscar algumas reflexões que discutem a questão sob diferentes perspectivas, e em acréscimo a estas constatações, nos parece ser viável pensar a comunicação assíncrona, via tempos em rede, como algo que possibilita que professor e alunos aproveitem e organizem melhor seu tempo.

O "tempo pedagogizado" aparece como uma categoria abstrata, relativa a um tempo sem variação. Por isso entendemos que a Educação a Distância, quando pensada no impulso criativo de um tempo de qualidade, o tempo Kairós, apropriando-se dos recursos do movimento, da imagem e do som, pode, certamente, ajudar na aprendizagem, sendo ponto de ligação ou conexão para uma maior compreensão de vida, que impulsiona e desenvolve as nossas capacidades, mediadas pelas tecnologias a serviço da educação.

Nessa perspectiva, o papel do professor supervisor pode ser analogamente comparado ao de um arquiteto. Mais do que propor uma forma para sua disciplina, no desenho curricular do curso, o professor é o responsável pela arquitetura de um espaço virtual de aprendizagem que coopera para a superação das distâncias e da visão de que educar vai além de uma boa transmissão de conhecimentos, colocando mais qualidade no processo do que quantidade, explorando o tempo Kairós bem mais do que o tempo cronológico. 
Nossa proposta neste trabalho é a de refletir sobre a atuação do professor supervisor no curso de Letras da Universidade de Brasília, mostrando os desafios e as possibilidades que as ferramentas tecnológicas permitem a fim de criar um espaço que aproxime as distâncias, em um tempo de qualidade, e propicie o desejo de aprender. Nesse ambiente, a criatividade e a interatividade tornam-se possíveis quando o professor se posiciona como o modelador desse espaço partilhado, onde o aluno não é colocado como consumidor de informação, mas como parte do processo educativo, coautor desse desenho curricular. Nesse espaço, quanto maior a interatividade, menor a possibilidade de desistências e maior a sua autonomia e desempenho acadêmico.

Nessa perspectiva é que precisamos lembrar das palavras de Villard e Oliveira (2005) que nos ensinam que dentro da história da Educação a Distância no Brasil, tem-se inicialmente, antes do advento da TIC, um aluno solitário tentando estabelecer relação pedagógica como material didático que, por sua vez, em muitos casos, era o único material acadêmico disponível e este, que em tantos outros casos, fez o papel de professor. Ou quando não, um aluno tentando estabelecer comunicações que dependiam de meios de comunicação presos às limitações do espaço e do tempo, dentro de um paradigma da educação informativa e instrucional. A utilização das novas tecnologias de comunicação e informação na educação foi "[...] o que permitiu libertar a Educação a Distância da perspectiva marcante instrucional e informativa" (VILLARD; OLIVEIRA, 2005, p. 54).

Depois de nossas palavras iniciais, gostaríamos de abrir a próxima sessão com uma reflexão acerca do tempo cronológico, que já tecemos algumas considerações, e o tempo Kairós, que será alvo de nossa atenção a partir de agora.

\section{Cronos e Kairós e a educação dos novos tempos}

Segundo a mitologia grega, Cronos, deus do tempo, devorava os próprios filhos para que nenhum deles pudesse um dia roubar-lhe o trono. Salvo pela mãe, Réia, Zeus conseguiu escapar ao trágico destino que o aguardava, vindo posteriormente a destronar o pai e a tornar-se rei dos deuses. Ao lembrar essa passagem mitológica nos deparamos com a constatação de que, por vezes, sentimos, na perspectiva de cumprir o calendário escolar entre programas e horários pré-fixados, que Cronos ainda continua reinando na educação.

A noção dominante de tempo que tem prevalecido na Universidade assenta-se sobre a prevalência de Cronos, cuja dimensão de temporalidade representa uma delimitação temporal a partir da qual se desenvolvem as atividades escolares. Como se o saber a ser germinado naquele espaço de tempo estivesse preso a uma linha delimitada pelo calendário, fixado no planejamento e amarrado aos blocos de aulas. Pode-se dizer, assim, que o currículo escolar no ensino presencial reflete uma expressão da noção de ordem temporal personificada por Cronos.

O mito de Cronos pode nos subsidiar com elementos simbólicos para refletirmos sobre a questão da temporalidade que nos limita no trabalho acadêmico, sobretudo se pensarmos sobre as características que o tempo pode assumir, inclusive como instrumento de poder. Nesse sentido, é preciso voltar à simbologia do mito para ponderarmos sobre o que representa a castração de Urano: a repressão da intuição e da criatividade, capazes de antever o futuro. De outro modo, ao engolir seus filhos, Cronos pretende resguardar o poder, controlando possibilidades e estabelecendo limites para o futuro. Todavia, para pensar na probabilidade de fugir do domínio de Cronos, a exemplo de Zeus, lembramos a possibilidade de chamar a figura de Kairós como alternativa para não sermos devorados pelo tempo, senhor absoluto do passado e do futuro.

Kairós, outra personagem da mitologia, é também uma antiga noção grega para referir-se a um aspecto qualitativo do tempo. Kairós, em grego, significa o momento apropriado. Na mitologia grega, Kairós representa uma ideia de movimento. Metaforicamente, ele descreve uma noção peculiar de tempo, uma qualidade complementar em relação à noção de temporalidade que Cronos representa. Kairós é o melhor instante no presente, porque representa um tempo não absoluto, contínuo ou linear, diferente do que propõe a concepção 
newtoniana refletida no tempo cronológico. Kairós é a dinâmica que simboliza o instante especial, o momento oportuno (GARCIA, 2006).

A dimensão temporal representada por Kairós tem seu significado associado ao saber "quando" e "como" utilizar o momento adequado. Seria o tempo qualitativo, enquanto Cronos é de natureza quantitativa. É nesta perspectiva que refletimos sobre a arquitetura de uma sala de aula em EAD.

\section{Tempos em rede. Tempos \& redes na construção de uma sala de aula sem paredes}

Falar do tempo aqui não é falar do relógio, mas do contínuo em que se desenvolve tudo o que é presente. Depois de Einstein, o tempo tornou-se relativo e perdeu sua envergadura de imutabilidade, levando-nos, assim, a outros limites, a outros espaços. Viajar no tempo sempre foi considerado delírio de sonhadores, mas pode se tornar realidade científica com o passar das décadas e séculos. Entretanto, em tempos de rede, viajar no tempo é impedir que Cronos prevaleça e que a criatividade seja limitada por um contador. Nesse sentido, a tecnologia surge como a grande mãe: Réia, a que supera o tempo e liberta o mundo da herança da castração e da limitação impingida pela linearidade e rigidez do tempo governado por Cronos, que ousou superar o pai Urano, cuja simbologia denota o aprisionamento da criatividade e do movimento. Nascer sem ter espaço de ação, vir à luz sem poder se manifestar. Eis a imagem da contenção provocada por Urano em sua tirania, sucedida por Cronos, que repete o modelo paterno para não perder o poder.

Viajemos para além da tecnologia, vislumbrando as possibilidades de seu uso em um reinado de Kairós: as TIC, como Réia, podem destronar Cronos, em tempo de educação a distância mediada por tecnologias, quando professores e alunos separados espacial e/ou temporalmente não se limitam à tirania cronológica.

A educação a distância pode ter ou não momentos presenciais, mas acontece fundamentalmente com professores e alunos separados fisicamente no espaço e ou no tempo, mas podendo estar juntos por intermédio de tecnologias de comunicação.

\section{Sala de aula sem paredes: por uma educação sem distâncias}

Em tempo de educação em rede, o tempo pedagógico assume a dimensão temporal dedicada à produção de vivências prazerosas de ser senhor e não escravo do tempo. No tempo pedagógico reina Kairós, no movimento das novas tecnologias da informação e comunicação, em conjunto com novos paradigmas educacionais, em que o aluno deve ser sujeito aprendente e não mais uma "tábula rasa" que deve ser preenchida pelo conhecimento vindo do professor. E este, destronado da condição de "dono do saber", é condutor do processo educacional e não mais reprodutor vivo do conhecimento.

Dessa forma, estende-se o tempo de sala de aula, sem efetivamente aumentar o tempo cronológico. Ao desenharmos uma sala de aula em EAD, vislumbrando uma educação sem distância, consideramos fundamental a reflexão inicial sobre como trabalhar com o apoio pedagógico em um ambiente não presencial, fazendo a ponte entre a técnica e a educação, entre uma linguagem e outra. Assim, interrogamo-nos como Moran (2003, grifo do autor):

Quando alunos e professores estão conectados, surgem novas oportunidades de interação, antes simplesmente impensáveis. O que vale a pena fazer quando estamos em sala de aula e quando estamos só conectados? Como combinar, integrar, gerenciar a interação presencial e a virtual? Como 'dar aula' quando alunos estão distantes geograficamente e podem estar conectados virtualmente?

E reportamo-nos também a questionamentos os quais fizemos em outro momento: nesse ambiente virtual e também de ludicidade poderá ser possível romper com a ordem que mantém inúmeras ações. Quais seriam esses rompimentos? Não sabemos, mas não é difícil supor que verdades estabelecidas pela instituição escolar e implementadas ao longo do tempo serão fortemente problematizadas. Fica-nos então a pergunta: Com que parâmetros podemos fazer considerações a respeito de um mundo a partir de uma relação homem-máquina, ou seja, a partir de uma realidade virtual? (RIBEIRO et al, 2005).

Em busca dessas respostas, destacamos os desafios que devem ser considerados nessa arqui- 
tetura de uma sala de aula, que tem como objetivo primordial aproximar distâncias geográficas, culturais, temporais e pedagógicas. Um dos aspectos a ser lembrado é o nível de letramento dos atores envolvidos no processo de educação em relação ao conteúdo que deve ser trabalhado. Outro aspecto diz respeito às múltiplas inteligências e também aos velhos e novos paradigmas educacionais em contraponto com a rotina acadêmica.

Atualmente, nosso desafio é o de incorporar as tecnologias de informação e comunicação, as TIC, tendo em vista esses aspectos, sem incorrer no equívoco de aliar o recurso tecnológico à concepção empirista da educação.

O cotidiano da sala de aula é sempre instável e exige do professor a reinterpretação de cada situação problemática em decorrência do confronto da (in) experiência de lidar com a modalidade de educação não presencial com outra experiência já vivida, entendendo, numa concepção heraclitiana, que ambas são irrepetíveis.

Inicialmente, há que se considerar que as condições de ensino, em qualquer modalidade, mudam dia a dia e que não existe a segurança do que "dá certo", mesmo na educação presencial. Nessa perspectiva, o professor necessita ser um pesquisador que questiona o seu pensamento e a sua prática, que age reflexivamente em seu ambiente de trabalho, que toma decisões e cria respostas mais adequadas, porque elas são construídas a cada momento e em cada situação concreta.

Assim, instaura o processo de construção que vai elaborando pouco a pouco o novo conhecimento profissional, necessário na conformação de um espaço de interação educativa, possibilitando uma melhor compreensão da realidade e que reforça a responsabilidade pela decisão tomada.

Não podemos ignorar que o surgimento da EAD teve suas bases consolidadas no modelo fordista de produção, cuja proposta é a produção em larga escala para atender o consumo de massa. No campo da educação, essa lógica vai evidenciar-se na expansão da oferta de educação, inicialmente inaugurada com a universalização do ensino fundamental e médio e, mais tardiamente, ampliada para o ensino superior.

A tecnologia educacional constituiu-se, inicialmente, como uma disciplina de base e fundamentou a criação dos cursos de graduação em diversas áreas como âncora para o processo de inclusão de indivíduos que não teriam outra possibilidade de realizar um curso em nível superior. Inicialmente, encurtar a distância geográfica era a meta. A flexibilidade dos horários, a não obrigatoriedade da frequência diária, a utilização do computador como ferramenta, entre outros elementos, são condições que ampliam consideravelmente o leque de interessados em se incluírem em um processo de formação institucional. A distância física é encurtada pelas tecnologias de comunicação, que aproximam professores, alunos e tutores fisicamente distantes, mas não necessariamente aproximam saberes e interesses. Para tal é necessário, também, considerar o nível de letramento dos atores envolvidos no processo de educação em relação ao conteúdo que deve ser trabalhado no ambiente virtual de aprendizagem (AVA); as múltiplas inteligências e também a rotina acadêmica, uma vez que o tempo virtual não se sobrepõe ao tempo real e as exigências acadêmicas, sejam elas burocráticas ou pedagógicas, não se transformam nesse movimento de "virtualização" do tempo.

Concordamos com Lévy (2009) quando afirma que o virtual existe como potência, não é, portanto, um conceito oposto ao real, mas é oposto ao conceito atual. Assim, compreendemos que atualização e virtualização são dois conceitos diferentes. Lévy (2009, p. 17) define a atualização como "uma criação, invenção de uma forma a partir de uma configuração dinâmica de forças e de finalidades." A virtualização é oposta à atualização, uma vez que não se trata de uma solução, mas de uma "mutação de entidade", um deslocamento da entidade no espaço. Segundo Lévy (2009), para se compreender o virtual é preciso fazer a distinção entre estes quatro polos do conhecimento: o real, o possível, $o$ atual e o virtual.

O real está relacionado com a materialidade, pertence à ordem imediata das substâncias, das propriedades físicas e das determinações. Os objetos reais são perceptíveis aos nossos sentidos e têm seus limites claramente definidos. O possível existe apenas no plano das ideias. É quando um objeto tem sua existência apenas idealizada no plano abstrato de um projeto ainda não executado. Pode se tornar real, caso se materialize. 
O virtual é algo que existe em estado de latência e de potencialidade e não como um acontecimento da atualidade. $\mathrm{O}$ virtual, no contexto geral da EAD, evidencia a existência de um sistema mais caracterizado por suas potencialidades do que como uma fonte de soluções prontas e acabadas. Nesse sentido, a noção de virtualidade está fortemente associada à criatividade, e é nesse aspecto que o potencial educativo pode ter uma dimensão de qualidade, pois está mais próximo de uma proposta desafiadora do que de uma fonte de soluções para os problemas particulares. A dinâmica virtual possibilita novas oportunidades de criação diante de situações cujas soluções são resistentes às condições do momento considerado, assevera Pais (2004).

Para esse autor, o virtual não é o oposto do real, apenas possui uma realidade que lhe é própria, e sua natureza vai distanciar-se do atual pelo fato de não estar no território do imediato. Está próximo do possível, mas não é da mesma natureza, pois já tem implícita a resolução do problema, faltando apenas a realização. Assim, esses quatro polos do conhecimento: possibilidade, realidade, virtualidade e atualidade estão fortemente correlacionados. Os diversos movimentos envolvidos na passagem de um para outro desses polos caracterizam diferentes situações da aprendizagem de um novo conhecimento.

Compreendendo essas noções e concordando com Santos (2003, p. 109), que "a realidade virtual é o resultado da interação homem-computador”, assumimos que a abordagem do tempo Kairós está diretamente relacionada com a "quebra" da temporalidade, e com a noção de oportunidade, já que o aluno pode acessar o material em diversos momentos, de acordo com seu interesse e possibilidade. As orientações e aulas estão no AVA ininterruptamente e cabe ao aluno aproveitar o momento mais adequado para interagir com o material. A questão mais paradoxal é que a maior vantagem da EAD configura-se também como a razão do insucesso dos alunos. A liberdade de administrar o tempo e a flexibilidade propiciada pela metodologia e pelas ferramentas de interação, principal atrativo para os alunos que não podem ou não desejam frequentar as aulas em tempo cronológico e espaço concreto, torna-se o maior obstáculo no desenvolvimento da aprendizagem. A dificuldade em administrar esse tempo e a falta de percepção da noção espaço-tempo ou a redefinição dessas duas categorias provoca o isolamento e a sensação de abandono no aluno, pois, como pondera Harvey (1989, p. 275), “A compressão do tempo-espaço sempre cobra o seu preço da nossa capacidade de lidar com as realidades que se revelam à nossa volta".

$\mathrm{Na}$ concepção de uma sala de aula sem paredes, o professor precisa abandonar sua posição tradicional de transmissor de conhecimentos, enraizada numa disposição espaço-temporal linear e cronológica para se transformar num arquiteto de um espaço em construção permanente, em um orientador que se move na direção apontada pelo aluno e em um mediador que não impõe seu conhecimento, mas que propicia a interação.

Em outras palavras, o professor é um gestor de informações que serão transformadas em conhecimentos no amálgama possibilitado pelas ferramentas de interação, conteúdo, metodologias de aprendizagem e pelos saberes pessoais e profissionais dos alunos, ajustados de acordo com o potencial criativo que se ancora nas múltiplas inteligências dos atores da EAD.

Entretanto, observa-se que, quebrada a resistência inicial de integrar o quadro de professores de uma nova modalidade, na Universidade de Brasília, como na maioria dos programas de EAD, o professor é oriundo do ensino presencial da universidade e apresenta pouca ou nenhuma experiência na modalidade, embora tenha bastante experiência e domínio do conteúdo das disciplinas sob sua responsabilidade. Necessariamente, esses professores tiveram de mudar sua posição de mestre que tem o total controle de seu espaço acadêmico, que administra suas aulas, assumindo a posição de parceiro, pronto a mediar a receber o aluno no tempo em que esse considera oportuno.

Em vez de se atualizar em sua área específica, o professor passou a perceber que precisava se atualizar constantemente não só de sua disciplina. Assim, ele teve que sair do monólogo da sala de aula para o diálogo dinâmico e para a interação professor-conteúdo, proporcionado pelas diversas ferramentas do ambiente virtual de aprendizagem, abandonando o monopólio do saber para aderir à partilha de saberes e o isolamento individual para fazer parte da construção coletiva e processual do 
conhecimento, por meio da integração de conteúdos e mídias e dos trabalhos em equipes interdisciplinares e complexos.

Essa complexidade nas relações na EAD pode ser exemplificada pela quantidade de pessoal envolvido para ofertar apenas uma disciplina. Entre tutores, autores, revisores, coordenadores de tutoria, coordenadores pedagógicos, especialistas de EAD, webdesigners, dentre outros, a formatação final da disciplina torna-se uma construção coletiva. $\mathrm{O}$ que, inevitavelmente, potencializa os conflitos durante o processo.

Por outro lado, além de enfrentar o desafio da mudança de sair de sua zona de conforto de administrador único de seu espaço pedagógico, o professor precisa assumir a sua limitação em lidar com novas ferramentas e se dispor a conhecê-las, sabendo que, possivelmente, irá se deparar com alunos familiarizados com essas ferramentas dentre outros que, como ele, estão em processo de letramento digital.

Diante dessa perspectiva, enfrenta o desafio de deixar de ser autoridade para ser parceiro do aluno na construção de uma sala de aula, compreendendo inicialmente a mudança na aquisição do conhecimento provocada pelas tecnologias para se apropriar dos benefícios proporcionados por elas.
Usar tecnologias digitais para o desenho de um curso em EAD requer tempo, mudança de hábitos e costumes, implica mudanças nos currículos escolares, dedicação para adquirir novas habilidades ou competências, mas, sobretudo, requer um estudo epistemológico que sustente as práticas pedagógicas mediadas pelas tecnologias digitais. Isso significa que a mudança principal é a do papel do professor, já que é o professor no papel de constante aprendiz e facilitador que fará com que mude a forma de se dar aulas. Assim, ele tem a importante tarefa de construir o espaço pedagógico, numa arquitetura dinâmica e interativa.

À guisa de conclusão, para essas reflexões ainda em construção, apropriamo-nos do que afirma o escritor mexicano, prêmio Nobel de Literatura em 1990, Octávio Paz, para reafirmar que a EAD precisa ser pensada no impulso criativo de um tempo de qualidade, o tempo Kairós, pois o tempo não está fora de nós, nem é algo que passa diante dos nossos olhos como os ponteiros do relógio: nós somos o tempo, não são os anos que passam, mas nós que passamos. O tempo possui uma direção, um sentido, porque ele é nós mesmos.

"O ritmo realiza uma operação contrária à de relógios e calendários: o tempo deixa de ser medida abstrata e volta a ser o que é: algo concreto e dotado de uma direção" (PAZ, 1982, p. 69).

\section{REFERÊNCIAS}

GARCIA, J. Cronos e Kairós: repensando a temporalidade do currículo. 2006. Disponível em: <http://www. educacaoonline.pro.br/cronos_e_kairos.asp?f_id_artigo=117>. Acesso em: 20 fev. 2014.

HARVEY, D. Condição pós-moderna - uma pesquisa sobre as origens da mudança cultural. São Paulo: Loyola, 1989.

KENSKI, V. Memórias e formação de professores: interfaces com as novas tecnologias de comunicação. In: CATANI, D. Et al. Docência, memória e gênero: estudos sobre formação. São Paulo: Escrituras, 1997.

LÉVY, Pierre. Cibercultura. Trad. Carlos Irineu da Costa. São Paulo: Editora 34, 2009.

MORAN, José Manuel, MORAN, Juan Manoel. Educação inovadora presencial e a distância. 2003. Disponível em: <http://www.eca.usp.br/prof/moran/site/textos/tecnologias_eduacacao/inov.pdf > . Acesso em: 20 fev. 2014.

MORAES, Denis de. (Org.). Globalização, mídia e cultura contemporânea. Campo Grande, MS: Letra Livre, 1997.

PAIS, Luiz Carlos. Noção de virtualidade e o encanto desvairado da tecnologia na educação escolar. Revista Eletrônica da UNESC, Florianópolis, ano 2, n. 3, maio 2004. Disponível em: <http://www.unescnet.br/nip/Edicao_Anterior/Revista_Eletronica3/ARTIGOS/TEXTO10.asp>. Acesso em: 20 fev. 2014.

PAZ, Octavio. O arco e a lira. São Paulo: Cosaic Naify, 1982.

RIBEIRO, Ormezinda Maria. et al. Da janela virtual à janela real. Sala de aula sem paredes: a construção da prática pedagógica de professores do ensino superior no TELEDUC. 2005. Disponível em: $<$ http://www.abed.org. 
br/congresso2005/por/pdf/164tcf3.pdf>. Acesso em: 22 fev. 2014.

SANTOS, Laymert Garcia dos. Politizar as novas tecnologias: o impacto sócio técnico da informação digital e genérica. Rio de Janeiro: Editora 34, 2003.

VILLARD, Raquel; OLIVEIRA, Eloíza. Tecnologia na educação: uma perspectiva sócio-interacionista. Rio de Janeiro: Dúnya, 2005.

VIRILIO, P. O espaço crítico. Rio de Janeiro: Editora 34, 1993.

Recebido em: 29.05.2014

Aprovado em: 16.07.2014 